\title{
The use of Chinese traditional elements in the contemporary oil paintings
}

\author{
Zhuocai OUYANG \\ Academy of Fine Arts \\ Jiangxi Normal University \\ Nanchang, China
}

\begin{abstract}
How to balance the relationship between the Chinese traditional culture and contemporary art, attaches importance to broader and deeper use of traditional Chinese elements in modern oil painting, and explore contemporary oil paintings with national perception is the question that contemporary art creators should think about.
\end{abstract}

Keywords- Culture; painting; traditional elements

\section{INTRODUCTION}

As an "Exotic" art form, the oil painting was introduced to China with a fresh feeling in the late 19th century. It not only provided new aesthetic perception, but also pushed thought reform and society development. After tortuous development of early Chinese oil painting, it then entered a period of prosperity in recent years, a broad international communication of art enables artists to learn more about art information of the contemporary world, while the rapid development of economy and the remarkable improvement in people's lives has brought the artists the power to inspire and move forward. Although Chinese oil painting has experienced a certain degree of development in recent years, from the terms of the macro, the number of masterpieces from Chinese oil painting world is small, lacking of visibility and representation worldwide. The main reason for this weakness is that Chinese oil paintings are lack of the profound reflection of social changes and underutilize advantages of traditional Chinese culture in painting creation. In addition, over a very long period of time, the creation of Chinese oil paintings relied too much on the development of Western art, which cannot reflect Chinese unique ethnic and cultural characteristics and the highlights of their own cultural particularity. Therefore, the development of Chinese painting should be combined with traditional Chinese elements and show its own culture in full.

\section{THE SIGNIFICANCE OF USING TRADITIONAL CHINESE ELEMENTS IN CREATING OIL PAINTINGS}

Seeing many of the current art exhibitions, it is easy to find that the return to basics is a key feature of the development of modern art. In fact, primitive art and folk art are the best endorsements of prominent frankness and pristine nature, and these traditional elements are the best sources of artistic inspiration. Artistic behaviors should have creativity, giving the works vigor and vitality, and only if they have a strong vitality, can they catch and impress the viewers. If we compare tradition to the axis of the wheel, then the development of national art should be the wheel rotating on the axis. Artistic creation is not any unfounded, it needs tradition and other arts as nourishment and cornerstone. If the development of a national art is compared to a rotating wheel, then tradition should be its axis. When the wheel makes a full revolution, back to the origin or the starting point, its original form and structure changes, and the new one is continuously produced. The origin is the source of national aesthetic sense, which is fixed there to innovate through run-blending with the new form. For example, Chinese contemporary oil painting was originally introduced into China from the West, from the initial simply imitating the Western oil paintings to accepting the new manifestations of Western painting techniques and ideas. Today's Chinese oil painting had left fully imitating stage, and began trying to find its own unique language and status. Speaking about the artistic thought, the collision and blend between Chinese traditional culture and modern culture in Chinese oil industry is more and more common, and the use of Chinese traditional elements gain more and more attention; in terms of skills, oil paintings also begin to use ways of freehand and dip from Chinese painting the way through. These efforts and attempts to find the own language of Chinese painting and Chinese traditional elements, and to use it in oil paintings through processing and innovation will greatly promote the development of China's oil industry. Painting should reflect the cultural spirit of "out of clear water, lotus engraved by nature ", so painting with Chinese characteristics should be natural and not stiff. We should pay attention to our country's culture and spirits, traditional Chinese traditional painting can embody the national cultural art most, the Chinese nation has a long history cultural traditions of five thousand years, traditional Chinese painting can embody the art spirits of national culture most, the integration between people and natural that landscapes presented. The realm of "The harmony between man and nature," modeling "between like and not like" and achieving "similarity in spirit" and so are the Chinese aesthetic principles that the artists must comprehend and follow. 


\section{MANIFESTATIONS OF TRADITIONAL CHINESE ELEMENTS IN OIL PAINTINGS}

\section{A. Philosophical concept of traditional Chinese literary thought}

Ancient Chinese literati and artists are concerned about the nature a lot, and interpret the meaning of life and charm through natural form or ink. Most of them stands for the idea of" The harmony between man and nature," and strive for harmony and unity of subject and object. In the oil painting, we highlight Chinese traditional elements mainly through emphasizing on performance, in order to express the artist's inner feelings and thoughts, express emotion, and then express their own ideals of life and spiritual pursuit.

\section{B. Decorative elements with Chinese national characteristics}

China has a long history as an ancient civilization, its traditional moral values, religion and culture, aesthetics, and art model is regarded as excellent materials of art. For example, in the ancient Chinese paintings, porcelain, embroidery, screen, theater and lanterns are frequently used ethnic decorative elements.

\section{China's unique painting style}

Traditional Chinese painting by ink carrying the artists' quality of training and life comprehend, express a fun mood, while China ink technique itself also has a strong aesthetic value. Famous contemporary artist Huang Bin that "Five pens and seven inks", where "Five pens" means: flat, round, leaving, heavy, and change; "Seven inks" refers to: thick ink, light ink, break-ink, splash-ink, accumulate-ink, dark ink and left ink. "Five pens and seven inks" constitutes the peculiar beauty of Chinese ink painting and unique charm. For example, Chinese painting focus on freehand shape, diversity of composition, the plane of the space and interest of the ink and richness of lines.

\section{THE USE OF CHINESE ELEMENTS IN CONTEMPORARY OIL PAINTINGS}

The world is multicultural coexistence, and the existence of ethnic and cultural presence makes the world cultural diversity possible. Chinese elements are the spiritual part of the coagulation through long periods of time in Chinese history. The development of Chinese oil paintings must draw essence from Chinese traditional culture, using unique Chinese elements in the creating process of contemporary Chinese oil paintings to enhance the nationality of Chinese oil paintings.

Color performance is an important part of oil paintings. Both East and West have their own characteristics in color performance. Chinese paintings focus on "the experience of color" and "memory of color " on the use of color and attach much attention to the "conceptual" and symbolic unity. In general, Chinese paintings emphasis on painting beautiful nature with a simple color ink. However, contemporary oil painting, oil painting artists can not only learn the advantages of Chinese monochrome paintings but also develop a broader space to play in terms of color. For example, our painter Zhou's paintings are like pieces of a wealthy Chinese taste of Chinese painting, the use of color is also full of elegance, creating an Orient poetry. Again, the works of Haisu Liu are serene, as he borrowed the ancient Chinese painter Qichang Dong's method of drawing landscape in dark color without bone, which makes his work show a scene of beauty, but also has a strong visual effect.

Ink is the best part of Chinese painting, which element can be applied into oil painting. In other words, contemporary Chinese oil painting artists can do some innovation on the premise of not changing the nature of painting, by giving the oil paintings Chinese national style and ethnic characteristics, creating new paintings contain Chinese unique culture, so that the oil paintings can be full of Chinese traditional aesthetics and cultural spirits, so as to achieve the artistic conception with the integration of Chinese and Western art. According to the characteristics of the painting material, the painters can take the consciousness of traditional Chinese painting as a guide, but not stick to the form in the creating process, emphasize the expression of "meaning" and "spirit" of paintings, and focus on expressing the artist's subjective emotions. For example, our Chinese painter's masterpiece "Tashilhunpo," the painter portray the scene by reducing the levels of light and shade, make the work like something of writing on the brushwork, and the picture full of poetic, with a strong national identity. In addition, the painter's masterpiece "Grandpa's River" has a significant Chinese painting style in terms of brushwork and characterization, all which has made painting artists' learn and use of Chinese elements come true.

In the twentieth century, the Chinese traditional decorative elements are reflected in the oil painting. Chinese paintings emphasize on self-expression, while Western paintings emphasize on artistic conception and charm. Aldie was the great artist who absorbed Chinese painting elements in oil painting, who put traditional oriental decorative elements into his painting creation. In his works, we can see paintings with traditional Chinese painting style, screens, vases and sculptures and so on. In his works, he blended these art elements of Chinese style into Western oil paintings by gorgeous colors and skillful brushwork. Chinese decorative elements are produced in Chinese unique cultural and historical background, which is an important part of Chinese traditional culture. In the oil painting process, on the basis of combining the characteristics of Western oil paintings, Chinese painters can blend these decorative elements of Chinese national characteristics into oil paintings.

\section{TRADITIONAL CHINESE DESIGNED ELEMENTS SHOULD BE COMBINED WITH MODERN DESIGN CONCEPTS}

How to use traditional designed elements in modern design is an eternal topic. People today are facing a complex phenomenon, new, old, modern and ancient, foreign and national, intricately intertwined, so that people's aesthetic ideas and values of have gone through greatly profound changes. In this case, the traditional element have lost its original cultural background on which it once relied, its semantics might not arouse sympathetic response in modern 
times, and lose the appeal to the audience, too. Therefore, we cannot simply use the traditional elements, but should apply new ideas to summarize previous practical experience, that is to combine traditional cultural elements with modern design concepts. On this point, we can understand by the following: we should use the dialectical point of view to look at the traditional culture which is borne by the traditional elements. Through five thousand years, China's traditional culture is deeply rooted in the land of China, which is our most precious spiritual wealth. Therefore, when it comes to the traditional culture, neither can we totally absorb it, nor can our attitude be completely negative, we should adhere to the principle of "keep its essence and discard its dross ". We should put Chinese traditional cultural elements into contemporary design, study deep-seated cultural characteristics, and extract certain cultural essence and core,

\section{CONCLUSIONS}

The reflection of national characteristics in Chinese contemporary installation art are far more than these, there are many aspects such as symbolic signs, scenic, heritage, folk acrobatics, the great hero, etc., these are the excellent material on which artists can make full use of their talent and creativity, at the same time of reflecting the artists' personality, the clever use of the subject also fully demonstrated the essence of the national spirit. Only by absorbing the nutrients in the national culture can gorgeous flowers bloom, so can we give the world a better understanding of our culture and unique arts. Only a full understanding and awareness of our own cultural geographical features, can the works of arts belong to the world be created. In the point of new modern aesthetic view to re-examine the traditional culture, we should blend the "traditional Chinese elements" imperceptibly into the works, and show the overall sense of the work design. "Consciousness" behind Chinese traditional elements is the key that people are obsessed to its shape. The auspice symbolization that it contains applies equally to modern design and delivering modern design ideas. We should change, restructure, and renew the traditional elements, so as to bring in not only traditional shape and charm, but also modern design ideas in which way the traditional elements with some new significance of communication with the modern people, thus making traditional elements have continuous vitality and attractiveness in modern design. Integrating phenomenon arisen in the process of local culture and foreign culture collision and fusion, is a very important aspect of modern design. Due to the sharp increase of number of international exchanges and international trades, international awareness grows as well. This promotes the formation of an international visual language and makes the design with international characters of become an irresistible trend. Under this trend of internationalism, in fact, there are latent possibilities and opportunities for the development of national culture. This manifest itself in the design of internationalism, on one hand, diversified development, on the other hand. Under this kind of communication design appears unified changes, resulting in the situation of diversified development where the design conveys the basic vision well, which is bound to arouse the integration between foreign culture and the local culture. Therefore, in modern designs, only by combining the elements of traditional culture and modern concepts, people can be given the feeling of nationalization. If they can integrate with each other, the result is sure to bring out the best in each other and enhance the continuity of the life cycle. Market competition in the 21 st century is the competition of designs, while what behind the design contest is the culture competition. How to understand and apply traditional cultural elements profoundly deserves our intensive study.

\section{References}

[1] Mo Huibo. Chinese contemporary oil paintings of minority folk culture and art to explore the elements[D]. Xinjiang Normal University,2012.

[2] Tong Sin. Chinese contemporary oil painting using traditional elements[D]. Hefei University of Technology,2012.

[3] Zhang Yan. On the use of oil painting in Chinese traditional elements of[D]. Jilin College of the Arts,2013.

[4] Fusion DU Yu contemporary oil paintings and Chinese traditional culture [D]. Qingdao University of Science and Technology,2013.

[5] Xia Fuling. Chinese traditional elements of expression in contemporary painting and application of[D]. Central Academy of Fine Arts,2014.

[6] Wan Lu. Painting in Chinese traditional elements[D]. Sichuan University,2007.

[7] Ren Jie. Chinese contemporary oil paintings of "pictorial turn" research [D]. Guangxi Normal University,2010. 